\title{
Coronary Anatomy and Left Ventricular Ejection Fraction in Patients With Type 2 Diabetes Admitted for Elective Coronary Angiography
}

\begin{abstract}
Peter Ammann, ${ }^{1,2 *}$ MD, Hanspeter Brunner-La Rocca, ${ }^{2} \mathrm{MD}$, Thomas Fehr, ${ }^{3} \mathrm{MD}$, Thomas Münzer, ${ }^{4}$ MD, Markus Sagmeister, ${ }^{3}$ MD, Walter Angehrn, ${ }^{1}$ MD, and Hans Rickli, ${ }^{1}$ MD

Patients with diabetes mellitus (DM) have more severe coronary artery disease and a two- to fourfold higher risk for myocardial infarction and death as compared to patients without DM. In this study, we analyzed coronary anatomy, left ventricular ejection fraction, and cardiac risk factors in patients with DM referred for coronary angiography and compared them with findings in nondiabetic patients. Coronary anatomy was assessed in a total of 6,234 patients and left ventricular ejection fraction in a subset of $4,767(76.5 \%)$ patients. Diabetic patients ( $n=641)$ were older $(60.8 \pm 9.6$ vs. $58.5 \pm 10.5$ years; $P<0.0001)$ and had higher rates of hypertension (65\% vs. 47\%; $P<0.0001$ ). Three-vessel disease (DM $44.7 \%$ vs. no DM $25.4 \%$; $P<$ 0.0001 ) and reduced left ventricular ejection fraction (DM 58.4\% \pm 15.2 vs. no DM $63.9 \% \pm 13.2$; $\boldsymbol{P}<0.0001)$ were significantly associated with DM. After adjustment for age and other vascular risk factors, the presence of DM was associated with a higher atherosclerotic burden. We conclude that advanced coronary heart disease and left ventricular dysfunction are highly prevalent in diabetic patients, independent of age and other cardiovascular risk factors. Thus, cardiac assessment in diabetic patients should, in addition to optimal diabetic control, involve screening for left ventricular dysfunction. Catheter Cardiovasc Interv 2004;62: 432-438. ๑ 2004 Wiley-Liss, Inc.
\end{abstract}

Key words: diabetes; coronary angiography; left ventricular ejection fraction; sex; atherosclerosis; coronary artery disease

\section{INTRODUCTION}

An epidemic increase of patients suffering from type 2 diabetes mellitus (DM) has been observed in the United States and most of the Western countries over the last decade $[1,2]$. Diabetes is associated with a two- to fourfold higher risk for myocardial infarction and death [3]. The higher mortality rate observed in patients with DM cannot only be explained by a higher incidence of other risk factors for coronary artery disease such as smoking, hypertension, and hypercholesterolemia [3], with an incidence of macrovascular complications twice that of microvascular disease [4]. On the other hand, many studies of patients with coronary artery disease, including a high percentage of DM patients, have shown improved outcome with optimal medical therapy [5-11]. Taken together, these studies underline the importance of DM as a major risk factor for coronary artery disease and the potential for therapeutic interventions in these patients.

However, previous studies have provided controversial results regarding the association between the severity of coronary artery disease and the presence of DM [12-15]. Therefore, the aim of the present study was to assess the prevalence and severity of coronary artery disease in the largest cohort of diabetic patients yet studied in comparison with nondiabetic patients, consecutively referred to our center between 1990 and 2000. Additionally, we proposed that diabetic patients might have an impaired left ventricular ejection fraction as compared to nondiabetics as an important reason for their higher mortality rate beyond the risk factors for coronary artery disease.

${ }^{1}$ Division of Cardiology, Kantonsspital St. Gallen, St. Gallen, Switzerland

${ }^{2}$ Division of Cardiology, University Hospital Basel, Basel, Switzerland

${ }^{3}$ Department of Internal Medicine, Kantonsspital St. Gallen, St. Gallen, Switzerland

${ }^{4}$ Center for Geriatric Medicine and Rehabilitation Bürgerspital, St. Gallen, Switzerland

*Correspondence to: Dr. Peter Ammann, Department of Internal Medicine, Division of Cardiology, Kantonsspital St. Gallen, CH-9007 St. Gallen, Switzerland. E-mail: peter.ammann@kssg.ch

Received 18 September 2003; Revision accepted 2 March 2004

DOI 10.1002/ccd.20135

Published online in Wiley InterScience (www.interscience.wiley.com). 


\section{MATERIALS AND METHODS}

\section{Study Population and Technical Procedures}

Between January 1990 and December 1999, data from a total of 6,234 patients were collected with a computerassisted registry of all patients referred for coronary angiography to our hospital. Coronary angiography was performed by nine trained cardiologists in all patients using right and/or left Judkins angiographic procedures. Left ventricular angiograms were performed in a subset of $4,767(76.5 \%)$ patients in the right anterior oblique projection. In the remaining patients, angiograms were not done due to unstable clinical conditions such as acute coronary syndrome. All patients provided written informed consent for coronary angiographies and the local ethics committee approved the analysis of registry data.

\section{Quantitative Coronary Study}

Coronary anatomy was assessed by at least two senior cardiologists using a simplified scoring system derived from Dortimeter et al. [16]. Nine coronary segments were analyzed: the left main artery, four segments of the left descendent artery (proximal, middle, distal segment, and side branches), two segments of the circumflex artery, and two segments of the right coronary artery. Relevant coronary artery stenosis was defined as stenosis $>50 \%$. In addition, a more sophisticated scoring system was used to assess the atherosclerotic burden of each individual patient as described previously [14,17]: each of the nine segments was graded as follows: grade 0, angiographically normal segment; grade 1, <50\% stenosis; grade 2, 50-75\% stenosis; grade 3, 75-99\% stenosis; and grade 4, occlusion. Three scores were used to describe coronary atherosclerosis. The coronary score was defined by the number of coronary arteries exhibiting a stenosis greater than $75 \%$ (grades 3 and 4). Stenosis of the left main coronary artery $>50 \%$ was considered a two-vessel disease. The extent score was defined as the number of segments exhibiting stenoses greater $>50 \%$ (grade 2) adjusted to the nine-segment coronary model. The atherosclerotic score was calculated as the average severity of all analyzable segments. Left ventricular function was assessed using computerized calculations of angiographic data. According to the left ventricular ejection fraction, four groups of patients were identified: patients with normal ejection fraction $(>55 \%)$, patients with slightly impaired ejection fraction (41-55\%), patients with moderately impaired left ventricular ejection fraction (30-40\%), and patients with severely impaired ejection fraction $(<30 \%)$.

\section{Assessment of Risk Factors}

Clinical diagnosis of type 2 diabetes was established by reviewing the medical records of all patients. Body mass index (BMI), defined as body weight in $\mathrm{kg}$ divided by the
TABLE I. Characteristics of the Study Population

\begin{tabular}{|c|c|c|c|}
\hline Characteristic & $\begin{array}{l}\text { Diabetes } \\
(\mathrm{n}=641)\end{array}$ & $\begin{array}{l}\text { No diabetes } \\
(\mathrm{n}=5,593)\end{array}$ & $P$ \\
\hline Age, years & $60.8 \pm 9.6$ & $58.5 \pm 10.5$ & $<0.0001$ \\
\hline \multicolumn{4}{|l|}{$\mathrm{Sex}_{1}$} \\
\hline Female & $168(26)$ & $1,326(24)$ & 0.35 \\
\hline Male & $473(74)$ & $4,267(76)$ & \\
\hline Body mass index, ${ }^{a} \mathrm{~kg} / \mathrm{m}^{2}$ & $27.9 \pm 4.0$ & $26.5 \pm 3.5$ & $<0.0001$ \\
\hline History of smoking & $262(41)$ & $2,622(47)$ & 0.003 \\
\hline Hypercholesterolemia $^{\text {b }}$ & $510(79)$ & $4,283(77)$ & 0.097 \\
\hline Arterial hypertension ${ }^{\mathrm{c}}$ & $416(65)$ & $2,644(47)$ & $<0.0001$ \\
\hline Family history of CAD & $116(18)$ & $897(16)$ & 0.19 \\
\hline \multicolumn{4}{|l|}{ Angina prior to angiography } \\
\hline No angina pectoris & 147 (22.9) & $1,538(27.5)$ & 0.02 \\
\hline Stable angina pectoris & $378(58.9)$ & $3,110(55.6)$ & 0.11 \\
\hline Unstable angina pectoris & $116(18.2)$ & $945(16.9)$ & 0.48 \\
\hline History of myocardial infarction & $277(43.1)$ & $2,348(42)$ & 0.57 \\
\hline
\end{tabular}

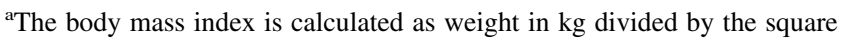
of the height in $\mathrm{m}$; it is indicated as mean $\pm \mathrm{SD}$.

${ }^{b}$ Defined as total cholesterol $>200 \mathrm{mg} / \mathrm{dl}$.

${ }^{\mathrm{c}}$ Defined as blood pressure $>140 / 90 \mathrm{~mm} \mathrm{Hg}$.

square of height in $\mathrm{m}$, was used as a measure of central obesity. Hypercholesterolemia was diagnosed if fasting blood samples of total cholesterol were above $200 \mathrm{mg} / \mathrm{dl}$ (5.0 $\mathrm{mmol} / \mathrm{L})$; hypertension was defined as repeated blood pressure measurements above 140/90 mm Hg.

\section{Statistical Analyses}

All data are expressed as mean \pm standard deviation or median with 25 th and 75 th percentile and as percentages or frequencies as appropriate. The Fisher's exact test was used to compare categorical data, number of vessels involved, and gender differences in diabetic and nondiabetic patients (Tables I and II, Fig. 1). Mann-Whitney statistics were used to compare coronary, extent, and atherosclerotic scores, left ventricular ejection fraction, as well as for calculation of continuous data in diabetic and nondiabetic patients (Tables I and III, Fig. 2).

Ordinal multivariate regression analysis was used to test independence of risk factors for the coronary artery disease (CAD) scores in multivariate analysis. Ordinal regression was used instead of linear regression because the number of categories and differences between the categories were not equivalent throughout the whole range of the $\mathrm{CAD}$ scores. Multivariate logistic regression analysis was used to calculate the impact of different risk factors and angiographic findings on impaired left ventricular ejection fraction (Table V). A two-tailed $P$ of $<0.05$ was considered statistically significant. A commercially available statistical program was used for analysis (SPSS 11.0 for Windows). 
TABLE II. Percentages of Segments With Stenoses > 50\% in Patients With Type 2 Diabetes Compared to Patients Without Diabetes in Respect to the Coronary Artery Anatomy

\begin{tabular}{|c|c|c|c|c|c|c|c|c|c|}
\hline \multirow[b]{2}{*}{ Stenoses $>50 \%$} & \multicolumn{3}{|c|}{ Diabetes $(n=641)$} & \multicolumn{3}{|c|}{ No diabetes $(\mathrm{n}=5,593)$} & \multicolumn{3}{|c|}{$\begin{array}{c}P \text { between male, female, } \\
\text { and overall }^{\mathrm{a}}\end{array}$} \\
\hline & $\begin{array}{c}\text { Female } \\
(\mathrm{n}=168)\end{array}$ & $\begin{array}{c}\text { Male } \\
(\mathrm{n}=473)\end{array}$ & Overall & $\begin{array}{c}\text { Female } \\
(\mathrm{n}=1,326)\end{array}$ & $\begin{array}{c}\text { Male } \\
(\mathrm{n}=4,267)\end{array}$ & Overall & Female & Male & Overall \\
\hline \multicolumn{10}{|l|}{ LAD } \\
\hline Proximal \% & 11.8 & 39.6 & 51.4 & 6.4 & 32.5 & 38.9 & & & \\
\hline Middle \% & 9.0 & 24.1 & 33.1 & 3.8 & 15.5 & 19.3 & 0.52 & 0.04 & 0.01 \\
\hline Distal \% & 3.0 & 10.9 & 13.9 & 1.2 & 6.5 & 7.7 & & & \\
\hline Side branches $\%$ & 9.2 & 30.1 & 39.3 & 4.6 & 23.5 & 28.1 & & & \\
\hline \multicolumn{10}{|l|}{$\mathrm{RCx}$} \\
\hline Main branch $\%$ & 9.5 & 36.6 & 46.1 & 5.0 & 25.5 & 30.5 & 0.1 & $<0.0001$ & $<0.0001$ \\
\hline Side branches $\%$ & 9.2 & 30.7 & 39.9 & 3.4 & 2.1 & 5.6 & & & \\
\hline \multicolumn{10}{|l|}{ RCA } \\
\hline Main branch \% & 12.5 & 43.3 & 55.8 & 6.6 & 34.4 & 41.0 & 0.6 & 0.06 & 0.07 \\
\hline Side branches $\%$ & 5.0 & 22.9 & 27.9 & 2.4 & 14.9 & 17.3 & & & \\
\hline
\end{tabular}

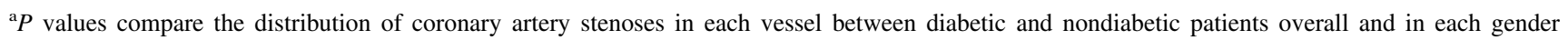
separately.

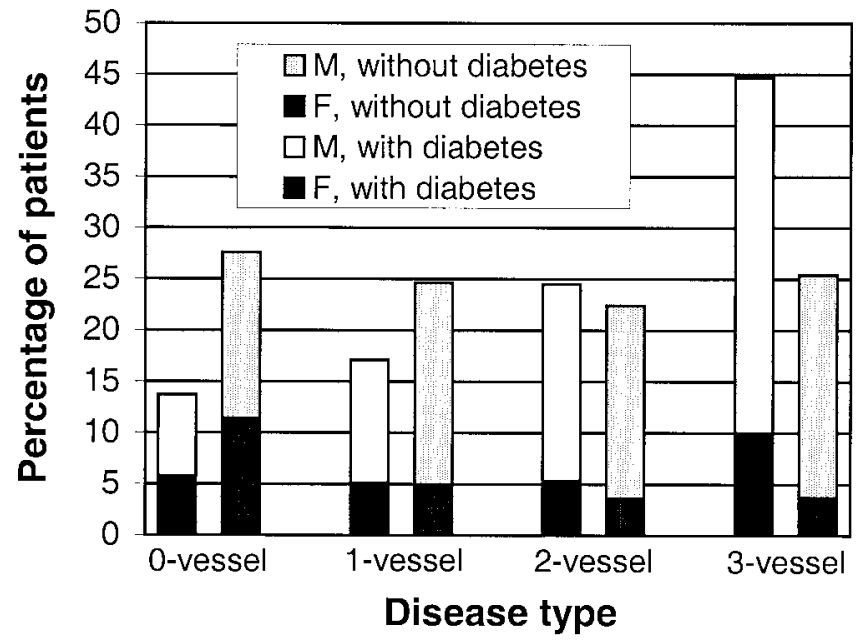

Fig. 1. Coronary artery anatomy in respect to sex and the presence of one-, two-, and three-vessel disease or normal coronary arteries. In the zero-, one-, two-, and three-vessel disease groups, statistical differences between diabetic and nondiabetic patients were as follows: for zero-vessel disease, $P=0.91$; one-vessel, $P=$ 0.02; two-vessel, $P=0.09$; and three-vessel, $P=0.002$. Gender differences between diabetic and nondiabetic patients in the zero-, one-, two-, and three-vessel disease groups were as follows: for female, zero-vessel disease, $P=0.0001$; one-vessel, $P=0.76$; two-vessel, $P=0.09$; and three-vessel $P=0.0001$; for male, zerovessel, $P=0.0001$; one-vessel, $P=0.0001$; two-vessel, $P=0.57$; and three-vessel, $P=0.0001$.

\section{RESULTS}

\section{Baseline Patient Data and Frequencies of Risk Factors}

Baseline clinical data of the study population are presented in Table I. Six hundred forty-one (10.3\%) of the 6,234 patients were diabetic. Patients with diabetes were older, had a higher body mass index, and were more frequently hypertensive, but smoked less often. Neither the presence of clinical symptoms prior to coronary angiography nor the history of a prior myocardial infarction differed between patients with or without diabetes.

\section{Coronary Anatomy}

Results of coronary anatomy summarized by sex and coronary stenoses $>50 \%$ are presented in Figure 1. Independent of sex, diabetic patients tended to have more often two-vessel (DM $24.5 \%$ vs. no DM $22.4 \% ; P=0.09$ ) and significantly more often three-vessel disease (DM $44.7 \%$ vs. no DM $25.4 \% ; P=0.002)$. In contrast, one-vessel disease was more frequent in patients without diabetes (no DM $24.6 \%$ vs. DM $17.1 \% ; P=0.02$ ). In the angiographic subgroups (zero-vessel, one-vessel, two-vessel, and threevessel disease), we found no gender differences between diabetic and nondiabetic patients (Fig. 1).

Distribution of segments with stenoses $>50 \%$ in the left anterior descending artery (LAD), the circumflex (RCx), and right coronary artery (RCA) is presented in Table II. Male patients with diabetes presented significantly more often with $>50 \%$ stenoses in the LAD as compared to patients without diabetes, whereas in women, no significant difference could be demonstrated. Furthermore, men had significantly higher rates of RCx stenosis. A similar trend was seen regarding RCA stenoses; however, the difference failed to reach statistical significance.

Differences in coronary atherosclerosis scores between patients with and without diabetes are shown in Table III. Diabetic patients presented significantly higher coronary, extent, and atherosclerotic scores as compared to patients without diabetes. In patients without diabetes, men had a significantly higher atherosclerotic burden than women. However, in diabetics we could not demonstrate such a difference except for a slightly higher atherosclerotic score (Table III). After adjustment for 
TABLE III. Differences in Coronary Atherosclerosis Scores Between Women and Men With and Without Diabetes*

\begin{tabular}{|c|c|c|c|c|c|c|}
\hline \multirow[b]{2}{*}{ Coronary scores } & \multicolumn{3}{|c|}{ Diabetes $(n=641)$} & \multicolumn{3}{|c|}{ No Diabetes $(\mathrm{n}=5593)$} \\
\hline & $\begin{array}{c}\text { Female } \\
(\mathrm{n}=168)\end{array}$ & $\begin{array}{c}\text { Male } \\
(\mathrm{n}=473)\end{array}$ & $P$ & $\begin{array}{c}\text { Female } \\
(\mathrm{n}=1,326)\end{array}$ & $\begin{array}{c}\text { Male } \\
(\mathrm{n}=4,267)\end{array}$ & $P$ \\
\hline Coronary score & $2(0-2)$ & $2(1-3)$ & 0.12 & $1(0-3)$ & $2(1-4)$ & $<0.0001$ \\
\hline Extent score & $3(1-4.25)$ & $3(2-5)$ & 0.06 & $1(0-1.33)$ & $2(0.33-1.44)$ & $<0.0001$ \\
\hline Atherosclerotic score & $1.4(0.67-1.78)$ & $1.4(0.78-1.89)$ & 0.05 & $0.67(0-1.33)$ & $0.89(0.33-1.44)$ & $<0.0001$ \\
\hline
\end{tabular}

*For each patient, a coronary, extent, and atherosclerotic score was calculated. Afterward, the median value and interquartile ranges for each score were calculated and presented. Note the highly significant gender differences in the coronary, extent, and atherosclerotic scores in nondiabetic patients. Concerning coronary and extent score, these differences are blunted by the presence of diabetes. All score differences between patients with and without diabetes are highly significant $(P<0.0001)$. Interquartile range in parentheses.



Fig. 2. Overall mean left ventricular ejection fraction is significantly worse in diabetic as compared to nondiabetic patients $(58.4 \% \pm 15.2$ vs. $63.9 \% \pm 13.2 ; P<0.0001)$. Patients are divided into different risk groups of normal ( $\geq 50 \%$ ), slightly impaired (41-49\%), moderately impaired $(30-40 \%)$, and severely impaired $(<30 \%)$ left ventricular ejection fraction.

age, gender, and other cardiovascular risk factors, these differences remained statistically significant (Table IV). In fact, the effect of diabetes on all the scores was not significantly influenced by the covariates.

\section{Left Ventricular Ejection Fraction}

Diabetic patients referred to coronary angiography had a significantly reduced left ventricular ejection fraction as compared to patients without diabetes $(58.4 \% \pm 15.2$ vs. $63.9 \% \pm 13.2 ; P<0.0001)$. Dividing patients into different risk groups of sudden cardiac death according to the studies of implantable defibrillators in coronary artery disease $[5,6]$, we found a significantly impaired left ventricular ejection fraction in the quartiles below $50 \%$ ejection fraction in diabetic compared to nondiabetic patients $(P=0.009$; Fig. 2). Additionally, the presence of diabetes mellitus was the second most independent risk factor for decreased left ventricular ejection fraction $(\mathrm{OR}=2.19 ; \mathrm{CI}=1.75-2.75$; $P<0.0001)$ after myocardial infarction $(\mathrm{OR}=3.68 ; \mathrm{CI}=$ $3.06-4.42 ; P<0.0001$ ) in multivariate analysis (Table $\mathrm{V}$ ). No gender differences could be observed in left ventricular
TABLE IV. Multivariate Ordinal Regression Analyses of Risk Factors for Prediction of Various Scores of Atherosclerosis $(n=6,234)^{\star}$

\begin{tabular}{lcrr}
\hline Scores & B & Wald & \multicolumn{1}{c}{$P$} \\
\hline Coronary score & & & \\
Sex & 0.413 & 45.9 & $<0.0001$ \\
Age & 0.172 & 33.9 & $<0.0001$ \\
Diabetes & 0.729 & 66.9 & $<0.0001$ \\
Hypertension & 0.167 & 12.9 & 0.0003 \\
Smoking & 0.205 & 17.9 & $<0.0001$ \\
Hypercholesterolemia & 0.392 & 40.1 & $<0.0001$ \\
Extent score & & & \\
Sex & 0.437 & 53.7 & $<0.0001$ \\
Age & 0.189 & 42.0 & $<0.0001$ \\
Diabetes & 0.823 & 83.3 & $<0.0001$ \\
Hypertension & 0.180 & 15.8 & 0.0001 \\
Smoking & 0.211 & 20.1 & $<0.0001$ \\
Hypercholesterolemia & 0.441 & 53.0 & $<0.0001$ \\
Atherosclerotic score & & & \\
Sex & 0.458 & 64.4 & $<0.0001$ \\
Age & 0.220 & 59.2 & $<0.0001$ \\
Diabetes & 0.853 & 101.6 & $<0.0001$ \\
Hypertension & 0.192 & 20.4 & 0.0001 \\
Smoking & 0.210 & 22.6 & $<0.0001$ \\
Hypercholesterolemia & 0.455 & 62.4 & $<0.0001$ \\
\hline
\end{tabular}

*Independent predictors of scores are shown. Predictors not statistically significant in multivariate analysis are not depicted. B denotes parameter estimate of each variable in ordinal regression model. Wald denotes importance of each variable as predictor of the scores (i.e., severity of coronary artery disease).

ejection fraction between patients with and without diabetes (data not presented).

\section{DISCUSSION}

To our knowledge, this is the largest angiographic study that systematically compared left ventricular ejection fraction and coronary artery anatomy in more than 6,000 patients with and without diabetes. The present study shows that, after myocardial infarction, the presence of diabetes itself is the strongest independent risk factor for left ventricular dysfunction. Additionally, we found an increased rate of advanced atherosclerosis in patients with DM, independent of age, sex, and other cardiovascular risk factors 
TABLE V. Multivariate Logistic Regression Analysis of Different Risk Factors and Angiographic Findings Associated With Impaired Left Ventricular Ejection Fraction $(<50 \%)^{\star}$

\begin{tabular}{lccc}
\hline $\begin{array}{l}\text { Risk factor or } \\
\text { angiographic finding }\end{array}$ & OR $(95 \% \mathrm{CI})$ & Wald & $P$ \\
\hline $\begin{array}{l}\text { History of } \\
\quad \text { myocardial }\end{array}$ & & & \\
$\quad$ infarction & $3.68(3.06-4.42)$ & 193.4 & $<0.0001$ \\
Diabetes mellitus & $2.19(1.75-2.75)$ & 46 & $<0.0001$ \\
BMI (per kg/m ${ }^{2}$ ) & $0.94(0.92-0.96)$ & 24.7 & $<0.0001$ \\
History of smoking & $1.26(1.07-1.49)$ & 7.5 & 0.006 \\
Atherosclerotic score & $1.12(1.00-1.25)$ & 3.6 & 0.05 \\
\hline
\end{tabular}

*Wald denotes the importance of each variable as predictor of the risk factors for left ventricular dysfunction. Predictors not statistically significant in multivariate analysis are not depicted.

such as hypercholesterolemia, hypertension, positive family history, and smoking. Patients with diabetes presented with a higher percentage of two- and three-vessel disease defined as coronary artery stenoses $>50 \%$ when compared to nondiabetics. Interestingly, in diabetic patients, atherosclerotic burden and severity scores were considerably less different between sexes when compared to patients without diabetes. This finding indicates that the protective effects of the development of atherogenesis of female sex are considerably reduced by the presence of diabetes. Still, male diabetics demonstrated more frequently peripheral coronary artery disease, while these differences could not be demonstrated in women. Taken together, our study demonstrates the paramount importance of DM as a risk factor for development and progression of coronary artery disease.

Multifactorial analyses of several prospective population studies have shown that the high incidence of coronary artery disease in DM patients cannot be explained by a higher incidence of other known risk factors as compared to the general population $[18,19]$. Our findings indicate that the severity of coronary artery disease is also notably influenced by the presence of DM, irrespective of other cardiovascular risk factors, age, and gender. Even after adjustment for these factors, DM was significantly associated with a more severe atherosclerotic burden as compared to patients without DM. However, there is some controversy in this regard in the literature. Whereas Ledru et al. [14] found similar results as in our registry, there are other reports that could not demonstrate a significant difference in the severity of coronary artery disease between diabetic patients and patients without diabetes $[15,20,21]$. The much smaller number of patients investigated compared to the present study may explain this discrepancy. Our study is the first that used established scores of the atherosclerotic burden determined by angiography in a large study population. The present findings of more severe coronary artery disease with higher atherosclerotic scores on angiogra- phy in patients with diabetes are confirmed in two recently published investigations by Ledru et al. [14] and Natali et al. [22], as well as two epidemiological studies $[23,24]$ that also found a more severe and diffuse coronary atherosclerosis in diabetic patients. The higher rates of diffuse disease found in these studies is in line with the higher frequency of three-vessel disease and the presence of peripheral coronary artery disease in our study population. In contrast to the study of Natali et al. [22], we were not able to detect a sex-specific pattern in coronary atherosclerosis in diabetic patients. The most likely explanation for this difference is the much higher number of diabetic patients investigated in the present study. This is supported by a larger angiographic study from Melidonis et al. [25], who also found no sex differences in diabetic patients concerning coronary artery anatomy.

Our finding of such a remarkable amount of left ventricular dysfunction in patients with diabetes is astonishing. The significantly higher rate of coronary artery disease in diabetic patients suggests that decreased left ventricular ejection fraction in diabetics may be due to more severe coronary artery disease. The fact that myocardial infarction was the strongest predictor for left ventricular dysfunction in multivariate analysis and the results of a large autopsy study [20], which found more myocardial lesions in diabetic as compared to matched nondiabetic patients, support this hypothesis. However, beyond myocardial infarction, the presence of diabetes alone was the second most important independent risk factor for decreased left ventricular ejection fraction. This suggests that diabetes itself leads to left ventricular dysfunction. Decreased left ventricular ejection fraction has also been shown in a small group of patients with insulin-dependent diabetes mellitus without coronary artery disease, and an impaired cardiac sympathetic innervation associated with a defective blunted recruitment of myocardial contractility leading to left ventricular dysfunction has been postulated [26]. Microvascular disease and the significantly higher presence of hypertension in diabetics as compared to nondiabetic patients may add to this condition. Whether poor control of blood sugar and associated glycosylation of cardiac myocytes add an additional burden is currently undetermined [27]. The overproportionally high percentage of DM patients (33\%) with severely impaired left ventricular ejection fraction included to the recently published trials of implantable cardioverter and defibrillators $[5,6]$ as compared to the routine prevalence of about $10 \%$ of diabetic patients referred to coronary angiography (10.3\% in our hospital) supports our data of a higher prevalence of left ventricular dysfunction in patients with diabetes admitted for elective coronary angiography. This suggests that diabetes is an important risk factor not only for the presence of coronary artery disease, but also for left ventricular dysfunction with a poor outcome by yet unknown mechanisms. Our find- 
ings are supported by other investigators who found that diabetes and arterial hypertension have adverse effects on left ventricular geometry and function, and that the combination of hypertension and diabetes resulted in the greatest degree of left ventricular hypertrophy and myocardial dysfunction [28]. However, coronary angiographies were not routinely performed in this study. In this context, it is noteworthy that $50 \%$ of patients with left ventricular dysfunction are asymptomatic [29]. Therefore, especially diabetic patients should be screened for left ventricular dysfunction even in the absence of clinical symptoms.

Previous studies using myocardial scintigraphy, treadmill stress test, or 24-hr heart rate variability have demonstrated a higher percentage of silent angina in patients with diabetes [30-32]. Autonomic impairment and abnormalities in pain perception have been advocated for it in diabetics. Interestingly, we could not demonstrate differences between diabetic and nondiabetic patients concerning their clinical symptoms when referred for coronary angiography, although coronary artery disease was significantly more severe in diabetics. This supports theories of an abnormal pain perception in patients with DM. It is tempting to speculate if abnormal pain perception was the main reason for the significantly higher age of diabetic as compared to nondiabetic patients referred for coronary angiography. However, due to the retrospective design of this study, a negative referral bias for coronary angiography in diabetic patients due to physicians' decisions cannot be excluded.

\section{Study Limitations}

In our study population, diagnosis of type 2 diabetes mellitus was based on information of patients, medical records, and blood glucose measurements in the majority of patients prior to coronary angiography. Information on the type of antidiabetic therapy and other cardiac medication was not systematically collected in our registry. Information on the duration of the disease, the glycemic control, other end-organ damage, or systematical follow-up investigations after coronary angiography is lacking.

In addition, coronary anatomy was assessed by angiography and not by intravascular ultrasound. Until now, there are only few studies giving insight into the role of diabetes on vascular remodeling and plaque accumulation in stenotic and nonstenotic coronary vessels [33,34]. In these studies, limited vessel remodeling could be demonstrated, but seemed to be confined to patients with type 1 diabetes. However, patients with type 2 diabetes showed a very similar plaque burden and vascular remodeling as compared to patients without diabetes at least in obstructive ( $>50 \%$ stenosis) lesions [33]. Therefore, coronary angiography seems to be an ade- quate method to detect coronary artery disease and atherosclerotic burden in patients with type 2 diabetes.

Patients with DM have significantly more severe coronary artery disease even after adjustment for age and other coronary atherosclerotic risk factors. In particular, DM is the most important risk factor for the severity of the disease. Furthermore, diabetic patients more often show left ventricular dysfunction as compared to nondiabetics, which is related to more severe and more diffuse atherosclerotic disease and to the presence of diabetes itself. Thus, diabetic patients with and without coronary artery disease may need more aggressive diagnostic and therapeutic efforts, irrespective of other cardiac risk factors and gender. Since the more diffuse nature of coronary disease in diabetic patients may make revascularization difficult or even impossible, slowing down progression of the disease by means of secondary prevention is particularly important in these high-risk patients. Future prospective studies are warranted to assess the long-term course of left ventricular function in newly diagnosed diabetics in relation to several strategies to modify additional risk factors.

\section{REFERENCES}

1. Mokdad AH, Bowman BA, Ford ES, Vinicor F, Marks JS, Koplan JP. The continuing epidemics of obesity and diabetes in the United States JAMA 2001;286:1195-2000.

2. Diamond J. The double puzzle of diabetes: why is the prevalence of type 2 diabetes mellitus now exploding in most populations, but not in Europeans? the genetic and evolutionary consequences of geographic differences in food history may provide the answer. Nature 2003;423:599-602.

3. Stamler J, Vaccaro O, Neaton JD, Wentwoth D. Diabetes, other risk factors, and 12-yr cardiovascular mortality for men screened in the Multiple Risk Factor Intervention Trial. Diabetes Care 1993; 16:434-444.

4. Turner R, Cull C, Holman R. United Kingdom Prospective Diabetes Study 17: a 9-year update of a randomized, controlled trial on the effect of improved metabolic control on complications in non-insulin-dependent diabetes mellitus. Ann Intern Med 1996; 124:136-145.

5. Moss AJ, Hall WJ, Cannom DS, Daubert JP, Higgins SL, Klein H, Levine JH, Saksena S, Waldo AL, Wilber D, Brown MW, Heo M. Improved survival with an implanted defibrillator in patients with coronary disease at high risk for ventricular arrhythmia: Multicenter Automatic Defibrillator Implantation Trial investigators. N Engl J Med 1996;335:1933-1940.

6. Moss AJ, Zareba W, Hall WJ, Klein H, Wilber DJ, Cannom DS, Daubert JP, Higgins SL, Brown MW, Andrews ML. Prophylactic implantation of a defibrillator in patients with myocardial infarction and reduced ejection fraction. N Engl J Med 2002;346:877883.

7. Garg R, Yusuf S. Overview of randomized trials of angiotensinconverting enzyme inhibitors on mortality and morbidity in patients with heart failure: Collaborative Group on ACE Inhibitor Trials. JAMA 1995;273:1450-1456. 
8. Packer M, Fowler MB, Roecker EB, Coats AJ, Katus HA, Krum H, Mohacsi P, Rouleau JL, Tendera M, Staiger C, Holcslaw TL, Amann-Zalan I, DeMets DL. Effect of carvedilol on the mortality of patients with severe chronic heart failure: results of the carvedilol prospective randomized cumulative survival (COPERNICUS) study. Circulation 2002;106:2194-2199.

9. CIBIS investigators and committees. A randomized trial of betablockade in heart failure: the Cardiac Insufficiency Bisporolol Study (CIBIS). Circulation 1994;90:1765-1773.

10. Sacks FM, Pfeffer MA, Moye LA, Rouleau JL, Rutherford JD, Cole TG, Brown L, Warnica JW, Arnold JM, Wun CC, Davis BR, Braunwald $\mathrm{E}$. The effect of pravastatin on coronary events after myocardial infarction in patients with average cholesterol levels: Cholesterol and Recurrent Events Trial investigators. N Engl J Med 1996;335:1001-1009.

11. Anonymous. Prevention of cardiovascular events and death with pravastatin in patients with coronary heart disease and a broad range of initial cholesterol levels: the Long-Term Intervention with Pravastatin in Ischemic Disease (LIPID) study group. N Engl J Med 1998;339:1349-1357.

12. Lemp GF, Vander Zwaag R, Hughes JP, Maddock V, Kroetz F, Ramanathan KB, Mirvis DM, Sullivan JM. Association between the severity of diabetes mellitus and coronary arterial atherosclerosis. Am J Cardiol 1987;60:1015-1019.

13. Henry P, Makowski S, Richard P, Beverelli F, Casanova S, Louali A, Boughalem K, Battaglia S, Guize L, Guermonprez JL. Increased incidence of moderate stenosis among patients with diabetes: substrate for myocardial infarction? Am Heart J 1997;134: 1037-1043.

14. Ledru F, Ducimetiere P, Battaglia S, Courbon D, Beverelli F, Guize L, Guermonprez JL, Diebold B. New diagnostic criteria for diabetes and coronary artery disease: insights from an angiographic study. J Am Coll Cardiol 2001;37:1543-1550.

15. Pajunen P, Nieminen MS, Taskinen MR, Syvanne M. Quantitative comparison of angiographic characteristics of coronary artery disease in patients with noninsulin-dependent diabetes mellitus compared with matched nondiabetic control subjects. Am J Cardiol 1997;80:550-556.

16. Dortimeter AC, Shenoy PN, Shiroff RA, Leaman DM, Babb JD, Liedtke AJ, Zelis R. Diffuse coronary artery disease in diabetic patients: fact or fiction? Circulation 1978;57:133-136.

17. CASS principal investigators. The National Heart, Lung, and Blood Institute coronary artery surgery study. Circulation 1981; 63:II1-II81.

18. Manson JE, Colditz GA, Stampfer MJ, Willett WC, Krolewski AS, Rosner B, Arky RA Speizer FE, Hennekens CH. A prospective study of maturity-onset diabetes mellitus and risk of coronary heart disease and stroke in women. Arch Intern Med 1991;151:1141-1147.

19. Rosengren A, Welin L, Tsipogianni A, Wilhelmsen L. Impact of cardiovascular risk factors on coronary heart disease and mortality among middle aged diabetic men: a general population study. $\mathrm{Br}$ Med J 1989;299:1127-1131.

20. Burchfiel CM, Reed DM, Marcus EB, Strong JP, Hayashi T.
Association of diabetes mellitus with coronary atherosclerosis and myocardial lesions: an autopsy study from the Honolulu Heart Program. Am J Epidemiol 1993;137:1328-1340.

21. Wilson CS, Gau GT, Fulton RE, Davis GD. Coronary artery disease in diabetic and nondiabetic patients: a clinical and angiographic comparison. Clin Cardiol 1983;6:440-446.

22. Natali A, Vichi S, Landi P, Severi S, L'Abbate A, Ferrannini E. Coronary atherosclerosis in type II diabetes: angiographic findings and clinical outcome. Diabetologia 2000;43:632-641.

23. Kannel WB, McGee DL. Diabetes and cardiovascular disease: the Framingham Study. JAMA 1979;241:2035-2038.

24. Krolewski AS, Warram JH, Valsania P, Martin BC, Laffel LM, Christlieb AR. Evolving natural history of coronary artery disease in diabetes mellitus. Am J Med 1991;90:56S-61S.

25. Melidonis A, Dimopoulos V, Lempidakis E, et al. Angiographic study of coronary artery disease in diabetic patients in comparison with nondiabetic patients. Angiology 1999;50:997-1006.

26. Scognamiglio R, Avogaro A, Casara D, et al. Myocardial dysfunction and adrenergic innervation in patients with insulin-dependent diabetes mellitus. J Am Coll Cardiol 1998;31:404-412.

27. Petrova R, Yamamoto Y, Muraki K, et al. Advanced glycation endproduct-induced calcium handling impairment in mouse cardiac myocytes. J Mol Cell Cardiol 2002;34:1425-1431.

28. Bella, JN, Devereux RB, Roman MJ, et al., for the Heart Study investigators. Separate and joint effects of systemic hypertension and diabetes mellitus on left ventricular structure and function in American Indians (the Strong Heart Study) Am J Cardiol 2001;87:12601265.

29. McDonagh TA, Morrison CE, Lawrence A, et al. Symptomatic and asymptomatic left-ventricular systolic dysfunction in an urban population. Lancet 1997;350:829-833.

30. Marchant B, Umachandran V, Stevenson R, Kopelman PG, Timmis AD. Silent myocardial ischemia: role of subclinical neuropathy in patients with and without diabetes. J Am Coll Cardiol 1993;22:1433-1437.

31. Langer A, Freeman MR, Josse RG, Armstrong PW. Metaiodobenzylguanidine imaging in diabetes mellitus: assessment of cardiac sympathetic denervation and its relation to autonomic dysfunction and silent myocardial ischemia. J Am Coll Cardiol 1995; 25:610-618.

32. Valensi P, Sachs RN, Harfouche B, et al. Predictive value of cardiac autonomic neuropathy in diabetic patients with or without silent myocardial ischemia. Diabetes Care 2001;24:339-343.

33. Vavuranakis M, Stefanadis C, Toutouzas K, Pitsavos C, Spanos V, Toutouzas P. Impaired compensatory coronary artery enlargement in atherosclerosis contributes to the development of coronary artery stenosis in diabetic patients: an in vivo intravascular ultrasound study. Eur Heart J 1997;18:1090-1094.

34. Kornowski R, Mintz GS, Kent KM, et al. Increased restenosis in diabetes mellitus after coronary interventions is due to exaggerated intimal hyperplasia: a serial intravascular ultrasound study. Circulation 1997;95:1366-1369. 